\title{
Multifaceted Rhizobacteria-Mediated Growth Augmentation in Chickpea
}

\author{
Poonam Kumari ${ }^{1} \cdot$ Veena Khanna ${ }^{2}$ Prafull Kumar ${ }^{3}$
}

Received: 30 May 2016/ Accepted: 27 June 2017/Published online: 12 July 2017

(C) The Author(s) 2017. This article is an open access publication

\begin{abstract}
Sixty-nine rhizobacteria isolated from chickpea rhizosphere were screened for their antagonistic potential against Fusarium oxysporum f. sp. ciceris under in vitro condition. Of these, 30 isolates inhibited growth of the pathogen and 13 potent antagonists were assessed for their functionality traits. Among the antagonistic traits exhibited by antagonists, production of diffusible antimetabolites insured its inhibitory effect on growth of test fungus as well as spore germination on solid media. Inhibition of fungus biomass in broth-based dual culture was revealed by 11 antagonists, while metabolic extracts of 5 isolates reduced the radial proliferation on solid media. Implication of biocidal volatiles in antagonism was demonstrated by 11 isolates; 3 produced cyanogenic volatiles, while all were ammonia producers. Investigation for hydrolytic activity demonstrated production of chitinase by 4 isolates and $\beta-1,4$-glucanase by 11 , while all were protease and amylase producers. Revealing the dual potential of bioantagonists, all the isolates tested positive for IAA and salicylic acid production, 7 for siderophore production while 10 were P-solubilizers and $8 \mathrm{Zn}$-solubilizers. Under glass house condition, bacterization of chickpea seeds with potential isolate Ps $14 \mathrm{c}$ alone and in consortium with Mesorhizobium ciceris reduced wilt incidence in pots (soil amended with $F$. oxysporum) to 48 and $28 \%$, respectively, as compared to uninoculated control (74\%) and also recorded appreciable increase in growth parameters. Present investigation clearly reveals the potential of rhizobacteria for use as bioinoculants.
\end{abstract}

Keywords Antagonism - Lytic enzymes - IAA - P-solubilization - Siderophore - Rhizobacteria - Bioinoculant . Soil amendment $\cdot$ Chickpea $\cdot$ Fusarium oxysporum

\section{Introduction}

Sustainable agriculture amalgamates environmental health, economic feasibility and social equity ensuring long-term productivity of natural resources and improved livelihood. It helps reduce the risks of complexities like climate

Poonam Kumari

poonam15sep@gmail.com

1 Department of Microbiology, Punjab Agricultural University, Ludhiana, Punjab 141004, India

2 Department of Plant Breeding and Genetics, Punjab Agricultural University, Ludhiana, Punjab 141004, India

3 Indira Gandhi Agricultural University, Raipur, Chhattisgarh, India unpredictability and climate change. Conventional agriculture which involves injudicious and inappropriate use of agrochemicals has resulted not only in the deterioration of soil health but also has led to some major environmental problems, such as soil and water pollution and other healthrelated problems, besides leading to increased cost of inputs for crop production. The challenge of enhancing productivity while retaining environmental soundness requires urgent need to integrate alternatives to agrochemicals. In this context, bioagents share would be considered a viable option. Numerous soil bacterial species which flourish in the rhizosphere of plants, but which may grow in, on, or around plant tissues, and stimulate plant growth by a plethora of mechanisms are collectively known as plant growth-promoting rhizobacteria (PGPR) [28]. Insight into the mechanisms operative at different 
stages of plant growth include increased mineral nutrient, nitrogen fixation, repression of soil-borne pathogens (via production of hydrogen cyanide, siderophores, lytic enzymes, antibiotics, and/or competition for nutrients), improving plant tolerance to abiotic stresses by producing enzyme 1-aminocyclopropane-1-carboxylate (ACC) deaminase and producing phytohormones such as indole-3acetic acid (IAA) and gibberellins [12].

Chickpea (Cicer arietinum L.) is the third largest produced food legume globally, India, being the largest producer [9]. Unprecedented use of agrochemicals (fertilizers and pesticides) to maximize its productivity has brought grave threats to the inborn soil fertility which has reached a plateau from where fertility status could not be increased even by increasing their dosage [15]. Moreover, the emerging demand for chemical-free food and necessity to achieve sustainability in agriculture within a holistic vision to focus on environmental protection has made possible exploitation of soil microorganisms for improving the crop health. Use of microorganisms presents an economically feasible and ecologically sound practice to enhance crop yield. In order to frame this practice into practical application, the present investigation was planned to isolate PGPR from rhizospheric soil, to elucidate different mechanisms implicated in plant growth promotion and antagonism and to study their effect on plant heath.

\section{Materials and Methods}

\section{Isolation and Screening of Rhizobacteria Antagonistic to Fusarium oxysporum f. sp. ciceris (Foc)}

A total of 36 soil samples were collected from rhizosphere of different chickpea fields [16]. Plants were cautiously excavated using a shovel, and the soil loosely attached to the root was collected as rhizosphere soil. The samples were then placed into prelabelled translucent ziplock bags and maintained at ambient temperature. The rhizobacteria were isolated on King's B medium by serial dilution technique. The isolated colonies on agar plates differing in colony morphology were selected, purified by subculturing and maintained on respective slants at $4-5{ }^{\circ} \mathrm{C}$.

To select the antagonistic bacteria, a 5-mm disk of test fungus, $F$. oxysporum (Procured from Department of Plant Breeding and Genetics, PAU, Ludhiana) was placed at the center of agar plate containing PDA and Kings B in 2:1 ratio, while rhizobacterial isolates were streaked $3 \mathrm{~cm}$ apart from the fungal inoculum and plates were incubated at $25{ }^{\circ} \mathrm{C}$ for 7 days. Radial growth of the test fungus was measured, and percent growth inhibition was calculated. A control plate with fungus alone was used as control. The growth of pathogen was measured in terms of diameter, and percent inhibition was calculated as under:

$\%$ Inhibition $=(R-r) / R \times 100$

where $r$ is radial growth of fungus in dual plate and $R$ radial growth of fungus in control plate.

\section{Assessment of antagonistic potential of Rhizobacteria}

\section{Fungal Biomass Inhibition in Liquid Medium}

One milliliter of overnight grown bacterial culture and a 5 -mm disk of test fungus were inoculated in $50 \mathrm{ml}$ of potato dextrose broth and incubated at $25{ }^{\circ} \mathrm{C}$. Broth inoculated only with fungus disk served as control. The difference in dry weights of the fungus from dual and the control cultures was recorded after 5 days of incubation by passing through preweighed filter paper (Whatman no. 1) which was dried for $24 \mathrm{~h}$ at $70{ }^{\circ} \mathrm{C}$ and weighed. The percent reduction in weight of the test fungus was calculated.

\section{Production of Diffusible Antimetabolites}

Diffusible antimetabolites production by rhizobacteria was assayed by method of Montealegre et al. [21]. PDA plates covered with cellophane membrane were overlaid with nutrient agar and inoculated with $100 \mu \mathrm{l}$ of the potential bioantagonists. After incubation for $72 \mathrm{~h}$ at $25^{\circ} \mathrm{C}$, the membrane along with the bacterial growth was removed and a disk of pure culture of pathogen was placed at the center of the plate and the growth was measured after $72 \mathrm{~h}$. Effect of diffusible metabolites on spore germination was studied by spreading $1 \mathrm{~mL}$ conidial suspension $\left(10^{4}\right.$ conidia $\mathrm{ml}^{-1}$ ) of $F$. oxysporum on PDA following removal of cellophane membrane. Petri dishes were incubated at $24{ }^{\circ} \mathrm{C}$ for $6 \mathrm{~d}$, and germination was evaluated visually.

\section{Production of Antibiotic Compounds}

The antimetabolites from 72-h-old culture supernatants of rhizobacterial antagonists were extracted using ethyl acetate as solvent. After evaporating ethyl acetate at $40{ }^{\circ} \mathrm{C}$, extracts were dissolved in $1 \mathrm{ml}$ of $50 \%$ methanol and tested for growth inhibition of $F$. oxysporum in agar wells made in PDA medium; 50\% methanol alone served as control.

\section{Production of Volatile Antifungal Compounds}

The production of volatile antifungal compounds by the isolates was assayed by sealed plate method [10]. Overnight grown bacterial culture was spread on nutrient agar medium, and a second petri dish containing PDA was 
inoculated with a 5-mm plug of the test fungus and placed over the bacterial culture. The two plates were sealed with parafilm and incubated at $25{ }^{\circ} \mathrm{C}$. Control consisted of a petri plate containing PDA medium inoculated with $5-\mathrm{mm}$ plug of the test fungus placed over nutrient medium without bacteria. Radial growth of the test fungus was measured over 24-h intervals for a period of 5 days.

\section{Assessment of Inhibitory traits of Rhizobacteria}

\section{Production of $\mathrm{HCN}$}

Petri plates containing 10\% Trypticase soya agar (TSA) supplemented with $0.44 \%$ of glycine were inoculated with bacteria, and lid was roofed with filter paper wetted with $0.5 \%$ picric acid in $2 \%$ sodium carbonate. The plates were incubated at $28{ }^{\circ} \mathrm{C}$ for $3-5$ days. Change in color of the filter paper from yellow to orange-brown indicated cyanide production [5].

\section{Production of Ammonia}

Ammonia production was detected by adding Nessler's reagent $(0.5 \mathrm{ml})$ to $10 \mathrm{ml}$ of bacterial cultures grown in peptone water for $48-72 \mathrm{~h}$ at $30^{\circ} \mathrm{C}$. Development of brown to yellow color indicated ammonia production.

\section{Detection of Lytic Enzymes}

\section{$\beta$-1,4-Glucanase}

Plates containing minimum salts medium with $(1 \% \mathrm{w} / \mathrm{v})$ carboxy methyl cellulose (CMC) were spot inoculated with the rhizobacterial isolates. After incubating for $48 \mathrm{~h}$ at $30{ }^{\circ} \mathrm{C}$, the agar medium was flooded with an aqueous solution of Congo red for $15 \mathrm{~min}$, washed and visualized for zones of hydrolysis detecting $\beta$-1,4-glucanase.

\section{Chitinase and Protease}

The rhizobacteria were inoculated on plates with minimum salts medium containing $(1 \% \mathrm{w} / \mathrm{v})$ colloidal chitin and $(1 \%$ $\mathrm{w} / \mathrm{v}$ ) casein, respectively, incubated for $48 \mathrm{~h}$ at $30^{\circ} \mathrm{C}$, and formation of zones of hydrolysis indicated chitinase and protease production.

\section{Amylase}

The log-phase cultures were spotted on the plates containing starch agar medium and incubated at $28{ }^{\circ} \mathrm{C}$ for $48 \mathrm{~h}$. The petri plates were then flooded with Gram's iodine. The hydrolysis of starch was observed as a colorless zone surrounding the colonies against purple background.

\section{Assessment of Plant Growth Promotion Traits}

\section{Siderophore Production}

Siderophore production was assayed using chromeazurol $\mathrm{S}$ agar (CAS) [24]. Formation of yellow halo around bacterial colonies on purple background was considered as affirmative result. Siderophore index was calculated as the sum of colony diameter and the halo zone diameter/the colony diameter.

\section{Salicylic Acid (SA) Production}

For SA assay, bacterial cells grown in succinate medium were harvested by centrifugation at $8000 \mathrm{rpm}$ for $5 \mathrm{~min}$ and resuspended in $1 \mathrm{ml}$ of $0.1 \mathrm{M}$ phosphate buffer. Four milliliters of cell free culture filtrate was acidified with $1 \mathrm{~N}$ $\mathrm{HCl}$ to $\mathrm{pH} 2.0$, and $\mathrm{SA}$ was extracted in $\mathrm{CHCl}_{3}$. Four milliliters of water and $5 \mu \mathrm{l}$ of $2 \mathrm{M} \mathrm{FeCl}_{2}$ were added to the pooled $\mathrm{CHCl}_{3}$ phases. The absorbance of the purple iron-SA complex was read at $527 \mathrm{~nm}$. A standard curve was prepared with SA in succinate [19].

\section{IAA Production}

For qualitative assay of IAA, petri dishes containing Luria agar supplemented with $5 \mathrm{Mm} \mathrm{L-Trp}$ were inoculated with bacterial inoculums, then overlaid with an $82-\mathrm{mm}$-diameter disk of Whatman no. 1 filter paper and incubated at $27{ }^{\circ} \mathrm{C}$ for 2-4 days. Formation of pink coloration on addition of Salkowski's reagent over filter paper indicated IAA production. The results were analyzed visually on a three-point scale ( + low; ++ medium, +++ high), and diameter of pink halo was measured [6].

\section{P-Solubilization}

The P-solubilization ability of rhizobacterial isolates was tested by spot inoculating cultures on Pikovskaya agar medium (glucose, $10 \mathrm{~g} ; \mathrm{Ca}_{3}\left(\mathrm{PO}_{4}\right)_{2}, 5 \mathrm{~g}$; $\left(\mathrm{NH}_{4}\right)_{2} \mathrm{SO}_{4}, 0.5 \mathrm{~g}$; $\mathrm{NaCl}, 0.2 \mathrm{~g} ; \mathrm{MgSO}_{4} \cdot 7 \mathrm{H}_{2} \mathrm{O}, 0.1 \mathrm{~g} ; \mathrm{KCl}, 0.1 \mathrm{~g}$; yeast extract $0.5 \mathrm{~g} ; \mathrm{MnSO}_{4}$ and $\mathrm{FeSO}_{4}$ trace; D/W, 1 1; agar, $15 \mathrm{~g} ; \mathrm{pH}$ 7). The isolates forming halo zone around the colony were considered as phosphate solubilizers. Diameter of halo was recorded after 4 days of incubation.

\section{Zn-Solubilization}

The Zn-solubilization ability of rhizobacterial isolates was confirmed by formation of halo zone around colonies inoculated on modified Pikovskaya medium containing $1 \%$ insoluble $\mathrm{ZnO}$. Diameter of halo was measured after 4 days of incubation. 


\section{Morphological and Biochemical Characterization of Rhizobacterial Isolates}

The bacterial isolates were characterized based on colony morphology and biochemically by following Bergey's Manual of Systematic Bacteriology [26].

\section{Molecular Characterization as Pseudomonas sp.}

\section{DNA Extraction}

For bacterial DNA extraction, $5 \mathrm{ml}$ of overnight grown culture was centrifuged (10 $\mathrm{min}$ at $10,000 \mathrm{rpm})$. Pellet suspended in $650 \mu \mathrm{l}$ of extraction buffer (consisting of $250 \mathrm{mM} \mathrm{NaCl}, 100 \mathrm{mM}$ Tris-HCl, $100 \mathrm{mM}$ EDTA, 10\% SDS and $10 \%$ PVP; pH 8.0) was incubated at $65{ }^{\circ} \mathrm{C}$ for $30 \mathrm{~min}$ followed by addition of $100 \mu \mathrm{l}$ of potassium acetate buffer ( $\mathrm{pH} 4.5)$. Genomic DNA was extracted twice with 700-800 of chloroform isoamyl alcohol (24:1). 0.6 volume isopropanol was added to precipitate the nucleic acids and centrifuged at 10,000 rpm for $10 \mathrm{~min}$, and supernatant was carefully discarded by aspirating the isopropanol. Pellet was washed by adding $0.5 \mathrm{ml}$ ice cold $70 \%$ ethanol, airdried and dissolved in $100 \mu \mathrm{l}$ of sterile distilled water. Biophotometer was used to quantify the extracted DNA.

\section{PCR Amplification}

Polymerase chain reaction (PCR) was carried out to amplify 16S rRNA using Pseudomonas genus-specific primers. Reaction mixture consisted of Taq DNA polymerase 2 units; $\mathrm{Mg}^{++}$of $1.5 \mathrm{mM} ; 10 \times$ buffer; $0.2 \mathrm{mM}$ each of the four dNTPs and $30 \mathrm{ng}$ template DNA, 25 pmol each of the primers. Thirty-five amplification cycles were performed in an automated DNA thermocycler with the following parameters: denaturation at $94{ }^{\circ} \mathrm{C}$ for $1 \mathrm{~min}$, primer annealing at $52{ }^{\circ} \mathrm{C}$ for $1 \mathrm{~min}$, elongation at $72{ }^{\circ} \mathrm{C}$ for $1 \mathrm{~min}$ and final extension for $10 \mathrm{~min}$. Primer sequences were as follows:

Oligo1 Forward sequence-5'-GACGGGTGAGTAA TGCCTA-3'.

Oligo2 Reverse sequence-5'-CACTGGTGTTCC TTCCTATA-3'.

Five microliters of the PCR amplifications was run on $1.2 \%(\mathrm{wt} / \mathrm{vol})$ agarose gel electrophoresis in Tris-borateEDTA buffer ( $\mathrm{pH} 8.3)(1.5 \mathrm{~h}$ at $40 \mathrm{~V})$, stained with ethidium bromide and photographed on a UV transilluminator.

\section{Glasshouse Experiment}

Glasshouse experiment was conducted during the year 2013-2014 in Schools of Biotechnology, Punjab
Agricultural University, India, to study the influence of selected rhizobacteria exhibiting both plant growth promotion and antagonistic traits as seed bioinoculants alone and in consortium with Mesorhizobium ciceris on seedling emergence, growth parameters, and wilt incidence in chickpea. Medium black clayey soil collected from chickpea field, Punjab Agricultural University, Ludhiana, was autoclaved $3 \times\left(1 \mathrm{~h}, 12{ }^{\circ} \mathrm{C}\right)$ at 24 -h intervals, and $1 \mathrm{~kg}$ sterilized soil amended with microconidial suspension (1000 conidia $\mathrm{mL}^{-1}$ ) of $F$. oxysporum @ $50 \mathrm{ml} / \mathrm{kg}$ was filled per pot. Susceptible variety JG-62 of chickpea was procured from the Department of Plant Breeding and Genetics, Punjab Agricultural University, Ludhiana. Following surface sterilization with $0.1 \%$ mercuric chloride for $30 \mathrm{~s}$, seeds were washed 5-6 times with sterile distilled water and dried under stream of sterile air. Seeds were then soaked in $10 \mathrm{ml}$ of bacterial inoculum containing $3 \times 10^{8} \mathrm{cfu} \mathrm{mL}^{-1}$ for $3-4 \mathrm{~h}$, thereafter dried and sown @ 10 seeds/bag. Each treatment was replicated 7 times. For dual inoculation, PGPR and Mesorhizobium inoculum was mixed in 1:1 ratio. Wilt incidence and growth parameters including seed germination, plant fresh and dry weight, plant height and chlorophyll content were recorded. While plant weight and height were recorded at the time of harvest, chlorophyll content was determined on 25th day of germination as it shows drastic decline at the time of harvest.

\section{Statistical Analysis}

Experimental data were analyzed using standard analysis of variance (ANOVA) followed by Duncan's multiple range test (DMRT) using CPCS1 software. Differences were considered significant at the $p \leq 0.05$ level. Standard errors were calculated for all mean values.

\section{Results and Discussion}

The plant rhizosphere represents a versatile and dynamic ecological environment for notable microbes. These microorganisms not only interact with plants permitting their better growth through production of growth substances and enhanced mineral nutrition but also interact with other detrimental pathogens which hinder the normal development of plants. Exploiting these soil inhabiting bacteria as promising bioinoculants framed the basis of present investigation. With an aim to explore the diverse microflora, we collected the soil samples from different chickpea growing rhizosphere. From these, a total of 69 rhizobacterial isolates showing rapid growth on Kings B medium were isolated and subjected to preliminary screening for antagonism against $F$. oxysporum f. sp. ciceris. The in vitro dual plate-based assay carried out to test inhibitory action of 69 bacterial isolates 
revealed that bacterial antagonists were the natural resident of chickpea rhizosphere. However, this inhibitory trait was exhibited only by 30 isolates that too in the varying range of $4.0-48 \%$. As the main motive of present investigation was to develop bioinoculants with both bioantagonistic and biofertilizing traits, we selected the 13 best antagonists that inhibited growth of the test pathogen in the range of 23.3-48\% (Table 1) for the evaluation of antagonistic and plant growth promotion traits.

\section{Assessment of Inhibitory Traits}

The assessment of bacterial antagonists for fungal biomass inhibition under broth-based dual culture revealed that 11 out of 13 isolates inhibited growth of the pathogen as indicated by reduction in dry weight of the fungal biomass compared to control. Reduction in biomass of the test fungi was recorded in the range of 17.4-71.8\% (Table 1). The remark to conclude here was that most of the isolates (except Ps15a, Ps19d and Ps24d) recorded much higher reduction in biomass of test fungus than under dual plate assay. This may be attributed to the fact that broth-based environment allowed a synergistic expression of all the mechanisms involved in biocontrol from all the interacting sites. Concomitantly, variable responses in reduction in fungal biomass in broth culture as compared to dual plate assay have been reported as certain antifungal metabolites are induced or repressed by the absence or presence of pathogen [18]. In a similar study, Kumari and Khanna [16] reported 11.6-62.97\% reduction in proliferation of $F$. oxysporum by Bacillus sp. isolates from chickpea rhizosphere under broth-based technique.

In another set of experiment implicating the role of diffusible metabolites in growth inhibition of the test fungus, it was observed that precultures of 8 out of 13 rhizobacterial antagonists reduced the mycelial proliferation of test fungus in the range of $13.33-76.6 \%$ (Table 1), maximum being exhibited with Ps14c (76.6\%) followed by Ps29c (66.6\%). Likewise, when we spread the spore suspension of $F$. oxysporum over media containing diffusible bioactive metabolites of precultures of bacterial antagonists, conidial germination of the pathogen was inhibited as indicated by scanty fungal mycelial growth from spores compared to control plates where ample growth of fungus was observed. This clearly suggested that antibiosis is an important contributor to the antagonistic effect of these bacteria through the diffusion of antifungal compounds into the medium. In confrontation with the present finding, Martinez et al. [18] reported that plates containing exudates of precultured A. piechaudii, $P$. chlororaphis and S. griseus inhibited both mycelial growth and conidiation of Helminthosporium solani. Moreover, implication of diffusible bioactive metabolites such as phenazine, pyoluteorin, pyrrolnitrin and cyclic lipopeptides in antagonism is well documented [14].
Further revealing the involvement of antibiosis in antagonism through secretion of antibiotic like compounds by bacterial antagonists, metabolic extracts from the culture filtrate of the bacterial isolates dissolved in 50\% methanol restricted the growth of test fungus in the range of $31.8-50.0 \%$ as observed by the inhibition zone between the well containing extract and fungal growth. The antimicrobial compounds has been reported to induce fungistatis in phytopathogens, inhibit spore germination, lyse fungal mycelia or exert fungicidal effect by impairing electron transport chain [14]. Inhibition of fungal growth by only 5 isolates that too in lower range as compared to diffusible metabolites clearly indicated that production of antimicrobial compounds was largely influenced by the type of medium used. Martinez et al. [18] in their studies against $H$. solani have reported similar observations. Séveno et al. [25] reported that production of the antibiotic phenazine by Pseudomonas aureofaciens was six times higher in solid culture than with liquid culture.

Unveiling the role of biocidal volatiles in antagonism, 11 isolates inhibited the fungal radial proliferation under sealed plate assay, albeit with different effectiveness, maximum being recorded with isolate Ps-14c (39.5\%). A similar antifungal activity of volatile organic compounds by rhizobacteria has been reported as an antagonistic armor against phytopathogens by Giorgio et al. [11]. They confirmed the strong inhibitory activity of 6 rhizobacteria isolated from common bean via volatiles on fungal mycelium and sclerotia of Sclerotinia sclerotiorum. When tested for ammonia production which is reported to play a significant role in bioantagonism, all the isolates exhibited affirmative results (Table 2). The role of ammonia producing B. subtilis MA-2 and Pseudomonas fluorescens MA-4 in augmentation of biomass of medicinal plant Geranium has been reported by Mishra et al. [20]. In similar studies Samuel and Muthukkaruppan [22] reported ammonia production in $95 \%$ of strains isolated from the rhizosphere of rice, mangroves and soils contaminated by effluent. Assessment of rhizobacterial isolates for production of hydrogen cyanide $(\mathrm{HCN})$ showed confirmatory results with only 3 isolates, Ps $24 \mathrm{~d}$ being strongest producer as indicated by change in color of filter paper from yellow to orange (Table 2). The difference observed in fungal growth inhibition under sealed technique and production of different volatile compounds clearly suggests involvement of some more volatile compounds in antagonism. Ammonia and $\mathrm{HCN}$ along with other volatiles like dimethyl disulfide, dimethyl trisulfide methyl and ketone 2-propanone present an integrative part of the pool of biologically active volatiles attributable to antagonistic trait of rhizobacteria [11].

Supplementing our study on antagonistic behavior of rhizobacterial isolates, antagonists were assessed for the production of lytic enzymes. The rationale behind this investigation was that cell wall of fungi provides both protective and aggressive functions, and if it is removed or weakened, the 
Table 1 Evaluation of antagonistic potential against Fusarium oxysporum by rhizobacterial isolates

\begin{tabular}{|c|c|c|c|c|c|}
\hline \multirow[t]{2}{*}{ Isolates } & \multicolumn{5}{|c|}{$\%$ growth inhibition of Fusarium oxysporum } \\
\hline & $\begin{array}{l}\text { Under dual plate } \\
\text { technique }\end{array}$ & $\begin{array}{l}\text { Under broth-based } \\
\text { technique }\end{array}$ & $\begin{array}{l}\text { Due to diffusible } \\
\text { metabolites }\end{array}$ & $\begin{array}{l}\text { Due to ethyl acetate } \\
\text { extracts }\end{array}$ & $\begin{array}{l}\text { Due to fungicidal } \\
\text { volatiles }\end{array}$ \\
\hline Ps $4 \mathrm{~b} 1$ & $30.70 \pm 0.40$ & - & $13.33 \pm 0.52$ & $40.00 \pm 1.15$ & $30.70 \pm 0.61$ \\
\hline Ps7a & $33.30 \pm 0.57$ & $59.30 \pm 0.34$ & - & - & $33.30 \pm 0.34$ \\
\hline Ps13b & $32.50 \pm 0.28$ & $55.40 \pm 0.52$ & - & $50.00 \pm 1.70$ & $32.50 \pm 0.46$ \\
\hline Ps $14 \mathrm{c}$ & $48.00 \pm 0.52$ & $66.5 \pm 0.46$ & $76.60 \pm 1.5$ & $43.30 \pm 0.57$ & $39.50 \pm 0.40$ \\
\hline Ps14d & $30.70 \pm 0.52$ & $57.10 \pm 0.57$ & $15.0 \pm 0.28$ & - & $30.70 \pm 0.34$ \\
\hline Ps15a & $26.15 \pm 0.61$ & $17.46 \pm 0.23$ & $16.66 \pm 0.57$ & - & $6.15 \pm 0.57$ \\
\hline Ps16a & $29.23 \pm 0.57$ & $47.11 \pm 0.51$ & - & - & $9.23 \pm 0.28$ \\
\hline Ps19d & $33.30 \pm 0.46$ & $18.14 \pm 0.57$ & - & - & - \\
\hline Ps20b & $30.71 \pm 0.40$ & - & $13.33 \pm 0.42$ & & $10.70 \pm 0.40$ \\
\hline Ps24d & $33.30 \pm 0.23$ & $29.16 \pm 0.61$ & $30.00 \pm 0.57$ & $31.80 \pm 0.80$ & $33.30 \pm 0.23$ \\
\hline Ps $28 c$ & $23.30 \pm 0.34$ & $32.17 \pm 0.28$ & - & $33.30 \pm 0.17$ & $23.30 \pm 0.52$ \\
\hline Ps29c & $33.30 \pm 0.40$ & $71.87 \pm 0.52$ & $66.60 \pm 0.61$ & - & - \\
\hline P-I & $35.50 \pm 1.50$ & $20.75 \pm 0.40$ & $16.66 \pm 0.34$ & - & $33.30 \pm 1.50$ \\
\hline
\end{tabular}

Values represent mean $\pm \mathrm{SE}$ of three replications

fungi die unless they are osmotically protected. When assessed for chitinase production, only 4 isolates tested positive for it, Ps$20 \mathrm{~b}$ being the strongest producer. Among 13 bacterial antagonists, 11 produced $\beta-1,4$-glucanase, while all the isolates tested positive for production of protease and amylase (Table 2). Not surprisingly, isolate Ps14c which exhibited maximum fungal growth inhibition tested positive for all the lytic enzymes. The role of hydrolytic enzymes produced by rhizobacteria for their biocontrol activity is well documented [15]. In their report, Kumar et al. [15] confirmed the antagonistic behavior of Bacillus sp. BPR7 against all six test pathogens, viz. Macrophomina phaseolina, F. oxysporum, F. solani, Sclerotium sclerotiarum, Rhizoctonia solani and Colletotrichun sp. due to production of mycolytic enzymes, viz. chitinase, $\beta-1,3-$ glucanase and $\beta-1,4$-glucanase that degraded the components of fungal cell wall such as chitin, $\beta$-1,3-glucan and glucosidic bonds. Compant et al. [8] reported that the production of allelochemicals such as lytic enzymes and antibiotics by rhizobacteria favors colonization and antagonistic activity in the environment. The amylase has been reported to have only a discrete effect on phytopathogens cell wall as there is no report of the presence of starch in fungal cell wall. However, this enzyme plays a key role in the early phase of antagonistic association [4] and assists easy survival of microorganisms by mediating hydrolysis of most widely distributed starch or any other readily available related $\alpha$-glucan elsewhere [17].

\section{Assessment of Plant Growth Promotion Traits of Rhizobacterial Isolates}

In perspective of the present requirement of attaining sustainability in agriculture, the next part of experiment aimed at screening the bacterial antagonists for plant growth-stimulating traits. Of 13 isolates tested for siderophore production, 7 produced siderophore as evidenced by the formation of orange halo on CAS agar (Table 2). Isolate Ps14c maintained its dual potential with second highest siderophore index (2.82), first being observed with Ps20b (2.94). In support of the present finding, Akhtar and Siddiqui [2] reported siderophore production by Pseudomonas sp. isolated from chickpea rhizosphere in the range of $1.6-1.7 \mathrm{~cm}$. The twin role of siderophores in stimulating plant growth through enhanced host nutrition and by disease suppression by scavenging limited iron depriving phytopathogens of iron nutrition is well documented [12]. Chakraborty et al. [7] reported that $B$. megatherium from tea rhizosphere produced siderophores which contributed to plant growth promotion and disease reduction. All the isolates in the present study also produced salicylic acid in the range of $5.75-58.75 \mu \mathrm{g} / \mathrm{ml}$ (Table 2). Isolate Ps $14 \mathrm{c}$ produced substantial amount of salicylic acid $(28.74 \mu \mathrm{g} / \mathrm{ml})$ which in combination with other antagonistic and plant growth-promoting traits could benefit plants under biotic and abiotic stress. Role of salicylic acid in enhancement of drought and salt stress tolerance in plants and inducing host resistance against phytopathogens is well documented [27].

Rhizobacterial isolates confirmed their potential to solubilize phosphates and zinc by formation of hydrolytic halo zone around the colonies on solid medium supplemented with $\mathrm{Ca}_{3}\left(\mathrm{PO}_{4}\right)_{2}$ and $\mathrm{ZnO}$, respectively. Of 13 isolates, 10 exhibited phosphate-solubilizing potential, while 8 were Zn-solubilizers (Table 2). Highest P-solubilization potential was exhibited by isolate Ps19d with solubilization area of $4.91 \mathrm{~cm}^{2}$, while P-I showed highest Zn-solubilization potential $\left(3.14 \mathrm{~cm}^{2}\right)$. The varied solubilization potential of 
rhizobacterial isolates has been reported to be related to the location from which they are isolated [23]. Saravanan et al. [23] reported that zinc-solubilizing Bacillus sp. (ZSB-O-1) isolated from the sphalerite ore material showed higher solubilizing ability in the $\mathrm{ZnS}$ (sphalerite) ore containing medium due to their adherence with the ore particles. Moreover, the inability of P-solubilizing isolates Ps $14 \mathrm{c}$ and Ps7a to solubilize $\mathrm{Zn}$ showed their low $\mathrm{Zn}$ tolerance potential. Zinc although is an important nutrient at low concentration but is toxic at higher concentration, and its solubilization might limit the growth of the bacteria at higher level [23]. In spite of this, data in the literature have cited $\mathrm{Zn}$ and phosphate solubilization ability of rhizobacterial isolates. Eleven out of twelve isolates of Bacillus sp. from soybean rhizosphere showed phosphate-solubilizing ability [30], while only 3 of total 48 bacteria isolated from the rhizosphere of rice plants showed zones of clearance of Zn-solubilization on media supplemented with insoluble $\mathrm{Zn}$ as $\mathrm{ZnO}$ or $\mathrm{Zn}_{3}\left(\mathrm{PO}_{3}\right)_{2}$ [29]. This shows that although their occurs a plenty of microorganisms in soil but not all of them have biofertilizing traits, screening them for solubilization of inorganic and insoluble minerals will certainly help to reduce the load of harmful chemicals which are being used at an unprecedented rate to meet the nutrition of plants.

Expanding the horizon of biofertilizing traits of rhizobacteria, production of phytohormones presents another contributory factor in stimulating plant growth. The present investigation revealed the biosynthesis of IAA as one of the major growth-promoting attribute associated with all the rhizobacterial isolates; however, a great variation in quantity was observed as indicated by difference in the intensity of pink color developed (Table 2). The discrepancy in IAA producing ability of rhizobacteria depending upon species, strains, culture condition, growth stage and substrate availability is well documented [3]. In spite of such variation, IAA biosynthesis by rhizobacteria has been reported to be associated with rapid establishment of roots in young seedlings which increases their ability to anchor themselves to the soil and to obtain water and nutrients from their environment, therefore enhancing their likelihood for survival [3].

\section{Characterization of Rhizobacterial Isolates}

Bacterial antagonists were identified based on morphological observation and biochemical characterization using Bergey's manual of determinative bacteriology as reference. Isolates Ps15a, Ps16a, Ps19d, Ps29c and P-I showed the characteristic fluorescent green pigmentation on Kings $\mathrm{B}$ medium which has been proposed as general medium for the non-selective isolation and pigment production of Pseudomonas species. The pigments such as fluorescein, pyorubin and non-fluorescent blue pigment, pyocyanin are readily produced by culturing on Kings medium B. However, production of fluorescence by pseudomonads is not constant during incubation and not common to all species of this group. Biochemical characterization of the isolates showed that all were indole, methyl red, Voges-Proskauer negative and citrate and catalase positive. They also hydrolyzed starch and reduced nitrates. Based on these characteristics, isolates were tentatively classified as Pseudomonas sp. However, molecular characterization using Pseudomonas genus-specific primers showed amplification only in 4 out of 13 isolates and yielded a product of about 618 bp confirming their identity as Pseudomonas sp. Negative PCR results with nine tentatively assigned Pseudomonas isolates clearly show that great difference exists between the designed PCR method and phenotypical identification that proved them as Pseudomonas sp. Among PGPR, fluorescent pseudomonads occur commonly in the rhizosphere of plants and they have immense potential in agriculture for use as biofertilizer and biocontrol agent [1]. The investigation further concludes the existence of a wide range of microbial diversity in soil with enormous prospective to emerge as bioinoculant.

\section{Pot Experiment}

The potential of isolate Ps14c, superior in terms of both in vitro-assayed plant growth-promoting and bioantagonistic attributes, was tested under controlled condition as single inoculant and in consortium with chickpea nodulating $\mathrm{Me}$ sorhizobium ciceris in stimulating plant growth and managing wilt in $F$. oxysporum challenged chickpea plants. Corroborating our earlier results, it was observed that yellowing symptoms in non-bacterized pathogen inoculated pots appeared early in contrary to bacterized and fungicidetreated plants where symptoms of wilting was delayed. The initial protection offered by antagonist Ps14c could be attributed to production of lytic enzymes, different diffusible metabolites and antibiotics which might have inhibited the pathogen growth. The effect of seed bacterization with bioantagonistic agent was very much evident in terms of final wilt incidence which was reduced to $48 \%$ compared to $74 \%$ in uninoculated control and was comparable to treatment with fungicide captan where $46 \%$ of plants showed wilting. Consortium administration of bacteria with M. ciceris recorded maximum protection $(72 \%)$ against the disease which reflects the synergistic interaction between the bacterial inoculants (Table 3). The same kind of interaction has been observed by Hahm et al. [13] who reported that the degree of disease suppression was significantly increased where dual culture treatment was used. The reflection of seed bacterization on plant growth was also observed. Inoculation with isolate Ps14c alone and in consortium with rhizobia 


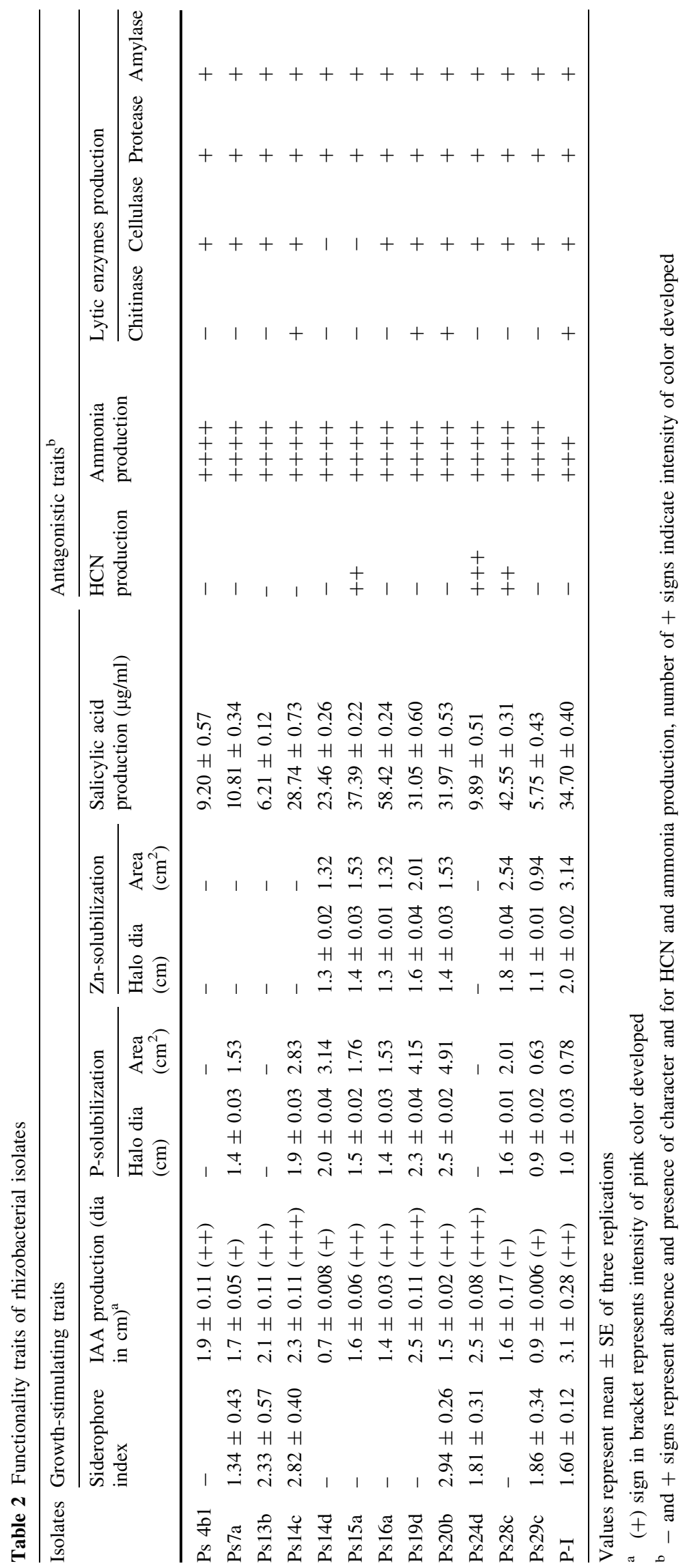


Table 3 Effect of seed treatment with bioagents on wilt incidence in chickpea

\begin{tabular}{llclc}
\hline Treatments & Wilt incidence $(\%)$ & & 30th day \\
\cline { 2 - 5 } & 20th day & 25th day & 17.2 & 35th day \\
\hline Ps14c + Rhizobium + Foc & 5.7 & 8.6 & 37.2 & 28.0 \\
Ps14c + Foc & 15.7 & 22.8 & 38.6 & 48.0 \\
Foc + fungicide & 11.4 & 22.8 & 50.0 & 76.0 \\
Foc (control) & 18.6 & 28.6 & 74.0 \\
\hline
\end{tabular}

Table 4 Effect of seed bacterization on growth parameters in chickpea

\begin{tabular}{|c|c|c|c|c|c|}
\hline Treatments & No. of seeds germinated ${ }^{\mathrm{a}}$ & Plant fresh weight (g) & Plant dry weight (g) & Plant height $(\mathrm{cm})$ & Chl content $(\mathrm{mg} / \mathrm{g})$ \\
\hline Ps14c + Rhizobium + Foc & $68(9.71)$ & $6.27^{\mathrm{a}}$ & $1.37^{\mathrm{a}}$ & $20.33^{\mathrm{a}}$ & $0.83^{\mathrm{a}}$ \\
\hline Ps14c + Foc & $66(9.57)$ & $5.90^{\mathrm{a}}$ & $1.26^{\mathrm{ab}}$ & $18.45^{\mathrm{b}}$ & $0.74^{\mathrm{ab}}$ \\
\hline Foc + fungicide & $63(9.00)$ & $5.75^{\mathrm{a}}$ & $1.18^{\mathrm{b}}$ & $17.4^{\mathrm{b}}$ & $0.66^{\mathrm{bc}}$ \\
\hline Foc (control) & $62(8.85)$ & $4.65^{\mathrm{b}}$ & $0.97^{\mathrm{c}}$ & $15.2^{\mathrm{c}}$ & $0.63^{\mathrm{c}}$ \\
\hline C.D (5\%) & NS & 1.05 & 0.13 & 1.4 & 0.11 \\
\hline
\end{tabular}

Value in bracket presents average number of seeds germinated

Each value represents mean $\pm \mathrm{SE}$ of three replications. In the same column, significant differences at $p<0.05$ levels are indicated by different letters. Data followed by same letter in the same column are not significantly different from each other according to analysis of variance (ANOVA)

${ }^{\text {a }}$ A total of 70 seeds were sown for each treatment @ 10 seeds/replication

recorded 95 and $98 \%$ seed emergence, respectively, as compared to $89 \%$ in control. Higher seed germination recorded in bacterized plants could be associated with auxin secretion by rhizobacteria which helped in root elongation and better survival of seedlings in the initial stage of growth. Plants also showed better growth in terms of plant height, plant fresh weigh and dry weight. Chlorophyll content recorded on 25th day of germination showed significantly higher values in dually inoculated plants as compared to uninoculated and fungicide-treated plants (Table 4). The benefit of using bioagent was clearly depicted in present investigation as fungicide treatment no doubt reduced wilt incidence in plants, but seed bacterization with isolate Ps14c offered dual benefit of plant growth stimulation and protection from wilt pathogen. This dual benefit was further stimulated on dual inoculation of bacterium and rhizobia resulting in enhanced shoot length, plant weight and photosynthetic ability of plants. This undoubtedly indicated active role of rhizobia in secretion of some plant growth-promoting hormones such as IAA and cytokinins. The similar synergistic effect in use of dual cultures is well documented in the literature [13].

\section{Conclusion}

Plant rhizosphere is rich depository of microorganisms; exploring this micro-biome to unravel an elite culture, having both biofertilizing and bioantagonistic traits, would offer sustainable agricultural benefits. This study presents a scrupulous approach to develop efficient bioagents for enhanced plant growth. However, further research on soilplant system is necessary to gain their commercial viability and worldwide acceptability.

Open Access This article is distributed under the terms of the Creative Commons Attribution 4.0 International License ( http://creativecommons.org/licenses/by/4.0/), which permits unrestricted use, distribution, and reproduction in any medium, provided you give appropriate credit to the original author(s) and the source, provide a link to the Creative Commons license, and indicate if changes were made.

\section{References}

1. Ahmad F, Ahmad I, Khan MS (2008) Screening of free-living rhizospheric bacteria for their multiple plant growth promoting activities. Microbiol Res 163:173-181

2. Akhtar MS, Siddiqui ZA (2009) Use of plant growth promoting rhizobacteria for the biocontrol of root-rot disease complex of chickpea. Aust Plant Pathol 38:44-50

3. Ashrafuzzaman M, Hossen FA, Ismail MR, Hoque MA, Islam ZM, Shahidullah SM, Meon S (2009) Efficiency of plant growthpromoting rhizobacteria (PGPR) for the enhancement of rice growth. Afr J Biotechnol 8:1247-1252

4. Azevedo AMC, De Marco JL, Felix CR (2000) Characterization of an amylase produced by a Trichoderma harzianum isolate with antagonistic activity against Crinipellis perniciosa, the causal agent of witches' broom of cocoa. FEMS Microbiol Lett 188:171-175

5. Bakker AW, Schippers S (1987) Microbial cyanide production in the rhizosphere in relation to potato yield reduction and 
Pseudomonas sp. mediated plant growth-stimulation. Soil Biol Biochem 1:415-457

6. Bric JM, Bostock RM, Silverstone SE (1991) Rapid in-situ assay for indole-acetic acid production by bacteria immobilized on a nitrocellulose membrane. Appl Environ Microbiol 57:535-538

7. Chakraborty U, Chakraborty B, Basnet M (2006) Plant growth promotion and induction of resistance in Camellia sinensis by Bacillus megaterium. J Basic Microbiol 46:186-195

8. Compant S, Duffy B, Nowak J, Clément C, Barka EA (2005) Use of plant growth-promoting bacteria for biocontrol of plant diseases: principles, mechanisms of action, and future prospects. Appl Environ Microbiol 9:4951-4959

9. FAO (2013) FAO statistical yearbook. Food and Agriculture Organization (FAO) of the United Nations, Rome, Italy. www.faostat.fao.org

10. Fiddman PJ, Rossall S (1993) The production of antifungal volatiles by Bacillus subtilis. J Appl Bacteriol 74:119-126

11. Giorgio A, Stradis AD, Cantore PL, Iacobellis NS (2015) Biocide effects of volatile organic compounds produced by potential biocontrol rhizobacteria on Sclerotinia sclerotiorum. Front Microbiol. doi:10.3389/fmicb.2015.01056

12. Gupta A, Gopal M, Tilak KV (2000) Mechanism of plant growth promotion by rhizobacteria. Ind J Exp Biol 38:856-862

13. Hahm MS, Sumayo M, Hwang YJ, Jeon SA, Park SJ, Lee JY, Ahn JH, Kim BS, Ryu CM, Ghim SY (2012) Biological control and plant growth promoting capacity of rhizobacteria on pepper under greenhouse and field conditions. J Microbiol 50:380-397

14. Hass D, Defago G (2005) Biological control of soil borne pathogens by fluorescent Pseudomonas. Nature 3:307-319

15. Kumar P, Dubey RC, Maheshwari DK (2012) Bacillus strains isolated from rhizosphere showed plant growth promoting and antagonistic activity against phytopathogens. Microbiol Res 167:493-499

16. Kumari P, Khanna V (2016) Allelopathic effect of native Bacillus sp. against Fusarium oxysporum causing chickpea wilt. Allelopath J 38:77-90

17. Marco JSD, Inglis MCV, Felix CR (2003) Production of hydrolytic enzymes by Trichoderma isolates with antagonistic activity against Crinipellis pereniciosa, the causal agent of witches broom of cocoa. Braz J Microbiol 34:33-38

18. Martinez TJ, Simard JN, Labonté J, Bélanger RR, Tweddell RJ (2006) The role of antibiosis in the antagonism of different bacteria towards Helminthosporium solani, the causal agent of potato silver scurf. Phytoprotection 87:69-75
19. Meyer JM, Abdallah MA (1978) The fluorescent pigment of Pseudomonas fluorescens: biosynthesis, purification and physiochemical properties. J Gen Microbiol 107:319-328

20. Mishra RK, Prakash O, Alam M, Dikshit A (2010) Influence of plant growth promoting rhizobacteria (PGPR) on the productivity of Pelargonium graveolens 1. Herit Recent Res Sci Technol 2:53-57

21. Montealegre JR, Reyes R, Perez L, Herrera M, Silva P, Besoain $X$ (2003) Selection of bioantagonistic bacteria to be used in biological control of Rhizoctonia solani in tomato. Electron $\mathrm{J}$ Biotechnol 6:116-127

22. Samuel S, Muthukkaruppan SM (2011) Characterization of plant growth promoting rhizobacteria and fungi associated with rice, mangrove and effluent contaminated soil. Curr Bot 2:22-25

23. Saravanan VS, Subramoniam SR, Raj SA (2003) Assessing in vitro solubilization potential of different zinc solubilizing bacterial (ZSB) isolates. Braz J Microbiol 34:121-125

24. Schwyn B, Neilands JB (1987) Universal chemical assay for the detection and determination of siderophore. Anal Biochem 160:47-56

25. Séveno NA, Morgan JAW, Wellington EMH (2001) Growth of Pseudomonas aureofaciens PGS12 and the dynamics of HHL and phenazines production in liquid culture, on nutrient agar, and on plant roots. Microbial Ecol 41:314-324

26. Sneath PHA (1986) Endospore forming gram positive rods \& cocci. In: Sneath PHA, Mair NS, Shrape ME, Holt JG (eds) Bergey's manual of systematic bacteriology. Williams \& Wilkins, Baltimore, pp 1104-1207

27. Tari I, Csiszar J, Szalai G, Horvath F, Pecsvaradi A, Kiss G, Szepesi A, Szabo M, Erdei L (2002) Acclimation of tomato plants to salinity after a salicylic acid pre-treatment. Acta Biol Szeged 46:55-56

28. Vessey JK (2003) Plant growth promoting rhizobacteria as biofertilizers. Pl Soil 255:571-586

29. Vaid SK, Gangwar BK, Sharma A, Srivastav PC, Singh MV (2013) Effect of zinc solubilizing inoculants on zinc nutrition of wheat (Triticum aestivum L.). Int J Adv Res 9:805-820

30. Wahyudi AT, Astuti RP, Widyawati A, Meryandini AA, Nawangsih AA (2011) Characterization of Bacillus sp. strains isolated from rhizosphere of soybean plants for their use as potential plant growth for promoting rhizobacteria. J Microbiol Antimicrobials 3:34-40 